this is most welcome, particularly for investigators working on strategies for cell replacement the United States, who must be feeling something of a déjà vu in face of yet another presidential moratorium, this time limiting the number of human stem cell lines that can be used for research and treatment. Ironically, this frustration recently led California voters to approve a $\$ 3$ billion initiative to fund stem cell research, which some have predicted will lead to a "gold rush" on stem cell research (9). Regardless of whether or not this proves to be the case, it can be hoped that this new initiative will serve as a beacon of hope for scientists and patients alike as we press ahead in this challenging area of science that appears to promise so much for the treatment of human diseases.

Address correspondence to: J. William Langston, The Parkinson's Institute, 1170 Morse Avenue, Sunnyvale, California 94089-1605, USA. Phone: (408) 734-2800; Fax: (408) 734-8522; E-mail: jwlangston@thepi.org.

\footnotetext{
1. Freed, C.R., et al. 2001. Transplantation of embryonic dopamine neurons for severe Parkinson's disease. N. Engl. J. Med. 344:710-719.

2. Olanow, C.W., et al. 2003. A double-blind controlled trial of bilateral fetal nigral transplantation in Parkinson's disease. Ann. Neurol. 54:403-414.

3. Kordower, J.H., and Sortwell, C.E. 2000. Neuropathology of fetal nigra transplants for Parkinson's disease. Prog. Brain Res. 127:333-344.
}

4. Studer, L., Tabar, V., and McKay, R.D. 1998. Transplantation of expanded mesencephalic precursors leads to recovery in parkinsonian rats. Nat. Neurosci. 1:290-295.

5. Isacson, O., et al. 2001. Cell implantation therapies for Parkinson's disease using neural stem, transgenic or xenogeneic donor cells. Parkinsonism Relat. Disord. 7:205-212.

6. Sanchez-Pernaute, R., Studer, L., Bankiewicz, K.S., Major, E.O., and McKay, R.D. 2001. In vitro generation and transplantation of precursor-derived human dopamine neurons. J. Neurosci. Res. 65:284-288.

7. Kim, J.H., et al. 2002. Dopamine neurons derived from embryonic stem cells function in an animal model of Parkinson's disease. Nature. 418:50-56.

8. Takagi, Y., et al. 2005. Dopaminergic neurons generated from monkey embryonic stem cells function in a Parkinson primate model. J. Clin. Invest. 115:102-109. doi:10.1172/JCI200521137.

9. Holden, C. 2004. U.S. science policy. California's Proposition 71 launches stem cell gold rush. Science. 306:1111.

\title{
Immune complexes as therapy for autoimmunity
}

\section{Raphael Clynes}

Department of Medicine and Microbiology, Columbia University, New York, New York, USA.

\begin{abstract}
For several decades, intravenous Ig has been used as treatment for a variety of immune-related diseases, including immune thrombocytopenic purpura (ITP), autoimmune neuropathies, systemic lupus erythematosus, myasthenia gravis, Guillain-Barré syndrome, skin blistering syndromes, and Kawasaki disease. Despite years of use, its mechanism of immunomodulation is still unclear. Recent studies using mouse models of ITP and arthritis, including one reported in this issue of the JCI (see the related article beginning on page 155), now provide some insights into this mechanism and the rationale for the development of Fc $\gamma$ receptor-targeted therapeutics.
\end{abstract}

\section{Fc receptors in the pathogenesis and treatment of ITP}

Intravenous Ig (IVIg) is remarkably effective in the treatment of immune thrombocytopenic purpura (ITP), with improved platelet counts seen in $80 \%$ of treated patients. ITP occurs in patients as the result of the generation of autoantibodies that bind to platelet surface antigens. These opsonized platelets are phagocytosed by Fc receptor-bearing splenic and hepatic macrophages (1). In the mouse, macrophage-mediated clearance occurs via activating $\mathrm{Fc}$ receptors, with complement-mediated uptake playing little or no role $(2,3)$. Thus, blockade of activating $\mathrm{Fc} \gamma$ receptors $(\mathrm{Fc} \gamma \mathrm{Rs})$ would be predicted to be an effec-

Nonstandard abbreviations used: $F_{c} \gamma \mathrm{R}, \mathrm{Fc} \gamma$ receptor; IC, immune complex; ITP, immune thrombocytopenic purpura; IVIg, intravenous Ig.

Conflict of interest: The author has declared that no conflict of interest exists.

Citation for this article: J. Clin. Invest. 115:25-27 (2005). doi:10.1172/JCI200523994. tive therapy in ITP. Indeed, this has proven to be a valid approach; antibodies that block FcyRIII have been shown to be effective in murine studies $(2,4)$ as well as in pilot clinical studies (5).

Although activating $F_{c}$ receptor blockade is an appealing mechanism, a second, unexpected FcyR-related pathway is clearly relevant to the therapeutic action of IVIg. It was recently shown (4) that the protective effect of IVIg is associated with upregulation of the inhibitory receptor Fc $\gamma$ RIIB on splenic macrophages and is abrogated in mice lacking Fc RIIB. Curiously, this effect is independent of SHIP and SHP-1 (6), the 2 downstream inhibitory phosphatases previously assumed to be responsible for the inhibitory signaling pathway. Redundant functions of SHIP and SHP-1 or other phosphatases downstream of Fc $\mathrm{RIIB}$ may be responsible (7), but as yet the FC $\gamma$ RIIB-mediated signal is unclear. Adding further to the mystery is the observation that 2 distinct macrophage populations are involved; IVIg protection requires CSF-1- dependent macrophages, whereas the macrophage responsible for Fc $\gamma$ RIII-mediated platelet clearance is CSF-1 independent (8). Thus, while other targets may prove effective in the treatment of immune complex-related (IC-related) autoimmunity $(9,10)$, at least 2 distinct $\mathrm{Fc} \gamma \mathrm{R}$ therapeutic approaches are tenable: direct blockade of the phagocytic Fc receptors and IVIg-triggered, Fc $\gamma$ RIIB-mediated inhibition (Figure 1).

\section{What is the active component of IVIg and intravenous anti-D?}

A related therapeutic, intravenous anti-D, has also been highly effective in ITP, but only in $\mathrm{Rh}^{+}$patients. The active component is clearly anti-D antibodies that generate large particulate ICs, namely opsonized rbcs, in $\mathrm{Rh}^{+}$ patients. In contrast, the active components in IVIg, a product obtained from sera pooled from thousands of donors, could conceivably include a variety of $\mathrm{Fc}$ receptor-binding ligands. In addition to the dominant species of monomeric IgG (which would bind FcRn and the high-affinity $\mathrm{Fc} \gamma \mathrm{RI}$ ), multiple types of ICs, which bind all $F_{C}$ receptors, are likely to form in vivo after the administration of IVIg. These complexes of varying valencies include cell-associated and soluble host antigens bound by donor natural antibodies as well as dimers and aggregated Igs formed in the IVIg product itself. Using mimetic modeling studies, Siragam et al. (11) suggest that the 2 therapeutics IVIg and anti-D have 

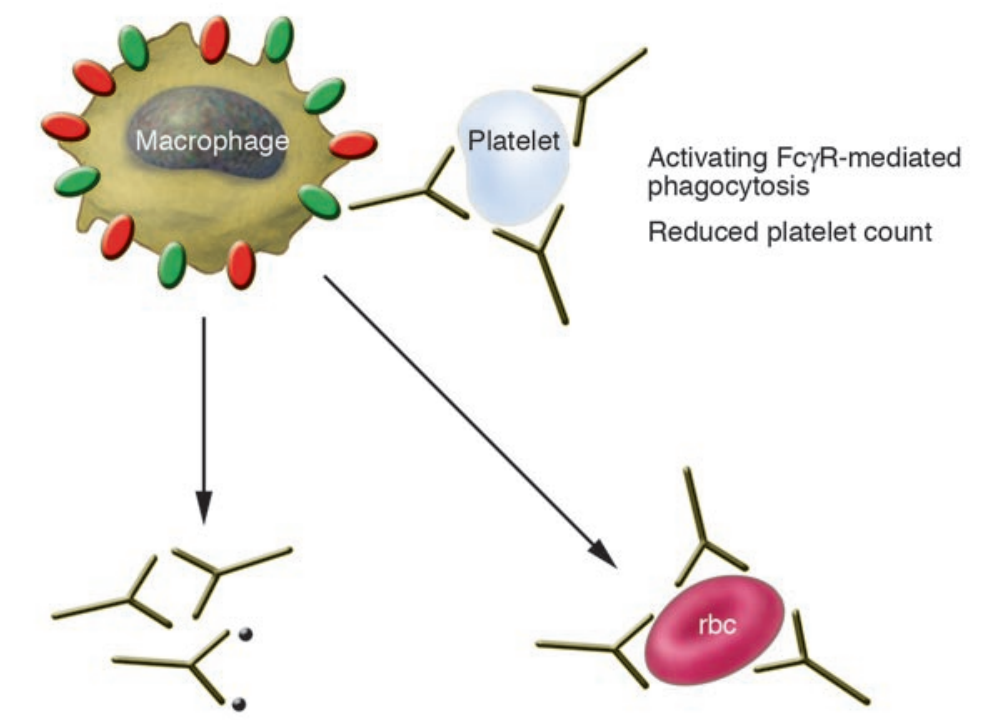

Soluble (small) ICs

FcyRII-dependent inhibition Upregulated FcyRIIB expression

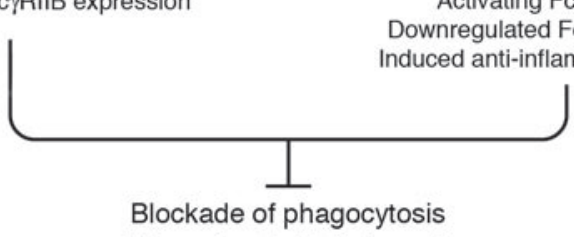

Normalized platelet count

\section{Figure 1}

Inhibition of phagocytosis in vivo can be accomplished via IC-mediated inhibition of Fc $\gamma$ R functional activity. These complexes, varying in size and valency, operate through distinct mechanistic pathways. IVIg leads to the formation of variably sized ICs, including small monomeric and dimeric complexes. The small ICs (Ig dimers or soluble antigen/donor Ig complexes) require CSF-1-dependent macrophages and FcyRII expression to mediate their as-yet-undefined antiinflammatory effect. Intravenous anti-D generates large particulate ICs, namely opsonized rbcs. These large ICs induce a phagocytic block in vivo in a manner independent of FcyRll expression. Perhaps mimicking the situation directly, antibodies that specifically engage either the inhibitory

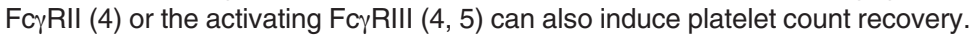

distinct mechanisms of action, either via small, soluble ICs or via large, particulate ICs.

The protective capacity of small ICs was found to be FcyRIIB dependent, which recapitulated results seen previously with the IVIg effect (4). This suggests that in contrast to anti-D, small ICs likely mediate IVIg protection. In contrast, as reported elsewhere (12), opsonized rbcs (anti-OVA/OVAcoupled rbcs) were capable of protecting against platelet clearance in both normal and FcyRIIB-deficient mice, which suggests that they interfere directly with activating Fc $\gamma$ R-mediated phagocytosis. The Fc $\gamma$ RIIBindependent anti-inflammatory mechanism of opsonized particulates might be assumed to be the straightforward result of activating FcyR blockade by antibody-coated rbcs. However, the fact that large increases in platelet counts are achieved with anti-D with little concomitant induction of anemia (13) suggests that there are other contributing mechanisms, including induction of cytokines and downregulation of activating FcyRIII (Figure 1) (12, 14-17).

\section{New approaches to Fc receptor therapeutics}

The implication is that IVIg is far from an optimized therapeutic. Thus, in addition to theoretical and practical concerns regarding safety, cost, and availability of this biologic, a better understanding of how the small IC component within IVIg exerts its therapeutic impact will drive development of an improved pharmaceutical product.
Targeting FcyRIIB directly by cross-linking FcyRIIB-specific antibodies has been shown to be beneficial in the mouse model of ITP, and injection of small, preformed ICs is also protective (18). The current work provides another potential solution, namely injection of antibodies with specificities for serum proteins including albumin and transferrin, which provide $\mathrm{F} c \gamma \mathrm{RII}-$ dependent protection (11). Monoclonal antibodies recognizing a single epitope form monomeric ICs, implying that clustering of $\mathrm{F}_{\mathrm{c}} \gamma \mathrm{Rs}$ by these small ICs is not required for their therapeutic effect. Even with polyclonal $\alpha$-albumin or $\alpha$-transferrin antibodies, the resultant ICs formed in vivo are still likely to be quite small, since the serum target proteins are present in such large molar excess. While this is an intriguing approach, an obvious concern is the potential for untoward ICtriggered hypersensitivity responses, which might complicate its clinical use.

\section{Implications for other autoimmune states}

Siragam et al. extend their observations beyond antibody-mediated thrombocytopenia in showing that both IVIg and its mimetic anti-murine albumin antibodies protect in the $\mathrm{K} / \mathrm{BxN}$ seruminduced arthritis model (11). The clinical benefit of IVIg has been spotty in autoimmune conditions, such as rheumatoid arthritis (19-24), in which autoaggressive T cells are believed to be the culprits. Recent attention in these $\mathrm{T}$ cell-mediated diseases, however, has been redirected toward the role of humoral immunity in the activation of $\mathrm{T}$ cells (25). Further, deficiency of activating Fc $\gamma$ Rs has been shown to be protective in classical T cell-mediated diseases, including arthritis (20-24) and experimental autoimmune encephalomyelitis (26-29), which suggests that Fc $\gamma$ R-based therapeutics might have as-yet-undiscovered clinical activity in $\mathrm{T}$ cell-mediated autoimmune conditions through regulatory effects on FcyR-bearing antigen-presenting cells. Identifying the critical FcyR mechanistic pathways hinted at by studies of IVIg may prove helpful in generating more effective pharmacologic agents and could widen the circle of patients possibly benefiting from Fc $\gamma$ R-targeted therapeutics. Thus, other autoantibody-driven diseases, beyond ITP, may prove treatable with a little of what ails you.

Address correspondence to: Raphael Clynes, Columbia University, P\&S Building, RM 8-510, 630 West 168th Street, New York, 
New York 10032, USA. Phone: (212) 305-5289; Fax: (212) 305-1392; E-mail: rc645@columbia.edu.

1. Alves-Rosa, F., et al. 2000. Treatment with liposome-encapsulated clodronate as a new strategic approach in the management of immune thrombocytopenic purpura in a mouse model. Blood. 96:2834-2840.

2. Clynes, R., and Ravetch, J.V. 1995. Cytotoxic antibodies trigger inflammation through $\mathrm{Fc}$ receptors. Immunity. 3:21-26.

3. Sylvestre, D., et al. 1996. Immunoglobulin G-me diated inflammatory responses develop normally in complement-deficient mice. J. Exp. Med. 184:2385-2392.

4. Samuelsson, A., Towers, T.L., and Ravetch, J.V 2001. Anti-inflammatory activity of IVIG mediated through the inhibitory Fc receptor. Science. 291:484-486

5. Clarkson, S.B., et al. 1986. Treatment of refractory immune thrombocytopenic purpura with an anti-Fc gamma-receptor antibody. N. Engl. J. Med. 314:1236-1239.

6. Crow, A.R., et al. 2003. IVIg-mediated amelioration of murine ITP via FcgammaRIIB is independent of SHIP1, SHP-1, and Btk activity. Blood. 102:558-560.

7. van Mirre, E., van Royen, A., and Hack, C.E. 2004 IVIg-mediated amelioration of murine ITP via FcgammaRIIb is not necessarily independent of SHIP-1 and SHP-1 activity. Blood. 103:1973-1974.

8. Bruhns, P., et al. 2003. Colony-stimulating factor-1-dependent macrophages are responsible for IVIG protection in antibody-induced autoimmune disease. Immunity. 18:573-581.

9. Akilesh, S., et al. 2004. The MHC class I-like Fc receptor promotes humorally mediated autoimmune disease. J. Clin. Invest. 113:1328-1333. doi:10.1172/JCI200418838.
10. Hansen, R.J., and Balthasar, J.P. 2002. Intravenous immunoglobulin mediates an increase in antiplatelet antibody clearance via the FcRn receptor. Thromb. Haemost. 88:898-899.

11. Siragam, V., et al. 2005. Can antibodies with specificity for soluble antigens mimic the therapeutic effects of intravenous IgG in the treatment of autoimmune disease? J. Clin. Invest. 115:155-160. doi:10.1172/JCI200522753.

12. Song, S., et al. 2003. Monoclonal IgG can ameliorate immune thrombocytopenia in a murine model of ITP: an alternative to IVIG. Blood. 101:3708-3713.

13. Scaradavou, A., and Bussel, J.B. 1998. Clinical experience with anti-D in the treatment of idiopathic thrombocytopenic purpura. Semin. Hematol. 35(Suppl. 1):52-57

14. Sutterwala, F.S., et al. 1997. Selective suppression of interleukin-12 induction after macrophage receptor ligation. J. Exp. Med. 185:1977-1985.

15. Sutterwala, F.S., et al. 1998. Reversal of proinflammatory responses by ligating the macrophage Fcgamma receptor type I. J. Exp. Med. 188:217-222.

16. Cooper, N., et al. 2004. Intravenous (IV) anti-D and IV immunoglobulin achieve acute platelet increases by different mechanisms: modulation of cytokine and platelet responses to IV anti-D by FcgammaRIIa and FcgammaRIIIa polymorphisms. Br. J. Haematol. 124:511-518.

17. Coopamah, M.D., Freedman, J., and Semple, J.W. 2003. Anti-D initially stimulates an Fc-dependent leukocyte oxidative burst and subsequently suppresses erythrophagocytosis via interleukin-1 receptor antagonist. Blood. 102:2862-2867.

18. Bazin, R., Lemieux, R., Tremblay, T., and St. Amour, I. 2004. Tetramolecular immune complexes are more efficient than IVIg to prevent antibodydependent in vitro and in vivo phagocytosis of blood cells. Br. J. Haematol. 127:90-96.

19. Maeda, H., et al. 2001. Successful treatment of "malignant rheumatoid arthritis" in Japan with pooled intravenous immunoglobulin. Rheumatology. 40:955-956.

20. Diaz de Stahl, T., et al. 2002. Expression of FcgammaRIII is required for development of collageninduced arthritis. Eur. J. Immunol. 32:2915-2922.

21. Ioan-Facsinay, A., et al. 2002. FcgammaRI (CD64) contributes substantially to severity of arthritis, hypersensitivity responses, and protection from bacterial infection. Immunity. 16:391-402.

22. Ji, H., et al. 2002. Arthritis critically dependent on innate immune system players. Immunity. 16:157-168.

23. Kaplan, C.D., et al. 2002. Development of inflammation in proteoglycan-induced arthritis is dependent on Fc gamma $\mathrm{R}$ regulation of the cytokine/chemokine environment. J. Immunol. 169:5851-5859.

24. Kleinau, S., Martinsson, P., and Heyman, B. 2000. Induction and suppression of collagen-induced arthritis is dependent on distinct fcgamma receptors. J. Exp. Med. 191:1611-1616.

25. Looney, R.J., Anolik, J., and Sanz, I. 2004. B cells as therapeutic targets for rheumatic diseases. Curr. Opin. Rheumatol. 16:180-185.

26. Abdul-Majid, K.B., et al. 2002. Fc receptors are critical for autoimmune inflammatory damage to the central nervous system in experimental autoimmune encephalomyelitis. Scand. J. Immunol. 55:70-81.

27. Lock, C., et al. 2002. Gene-microarray analysis of multiple sclerosis lesions yields new targets validated in autoimmune encephalomyelitis. Nat. Med. 8:500-508.

28. Pedotti, R., et al. 2003. Multiple elements of the allergic arm of the immune response modulate autoimmune demyelination. Proc. Natl. Acad. Sci. U. S. A. 100:1867-1872.

29. Robbie-Ryan, M., et al. 2003. Cutting edge: both activating and inhibitory $F_{c}$ receptors expressed on mast cells regulate experimental allergic encephalomyelitis disease severity. J. Immunol. 170:1630-1634.

\title{
SDF-1 tells stem cells to mind their P's and Z's
}

\author{
Connie J. Eaves
}

Terry Fox Laboratory, British Columbia Cancer Agency, Vancouver, British Columbia, Canada.

\begin{abstract}
Stromal cell-derived factor-1 (SDF-1) is a chemokine with unique functions, including a role in the trafficking of primitive blood precursor cells. A better understanding at a molecular level of how the binding of SDF-1 to its cell surface receptor, CXCR4, elicits specific biological responses in these cells has now been achieved through the identification of PKC- $\zeta$ activation as a common downstream signal. This finding suggests that treatment of a variety of clinical conditions might benefit from the targeting of $\mathrm{PKC}-\zeta$ (see the related article beginning on page 168).
\end{abstract}

\section{Overview of the regulation of stem/progenitor cell trafficking}

Throughout adult life, the production of blood cells is normally confined to particular sites within bone cavities where a

Nonstandard abbreviations used: PDK-1, phosphoinositide-dependent kinase-1; SDF-1, stromal cell-derived factor-1.

Conflict of interest: The author has declared that no conflict of interest exists.

Citation for this article: J. Clin. Invest. 115:27-29 (2005). doi:10.1172/JCI200424013. relatively small number of self-renewing hematopoietic stem cells that turn over slowly are also concentrated (1). In contrast, most of the cells circulating in the blood are highly specialized cells with little or no proliferative potential and a limited lifespan. However, not all hematopoietic stem cells and their primitive progeny are fixed in bone marrow niches. A small proportion of these cells continuously enter the blood and then rapidly return to the marrow (2). The distribution of primitive hematopoietic cells between the blood and bone marrow can also vary as a result of many perturbations and disease states. These include a variety of inflammatory conditions, leukemias, myelosuppressive treatments, and the administration of pharmacologic doses of hematopoietic growth factors. All of these conditions involve many physiological changes whose complexity has made it difficult to elucidate the molecular events that regulate the trafficking of primitive hematopoietic cells into and out of the bone marrow.

One fruitful approach came from early analyses of the molecular interactions between marrow stromal cells and primitive hematopoietic cells. This led to the identification of 2 pairs of molecular interactions that are important to the retention of primitive hematopoietic cells in the bone marrow: VCAM-1 with very late antigen-4 (VLA-4) and membrane-bound Steel 